\title{
Conditional corticotropin-releasing hormone overexpression in the mouse forebrain enhances rapid eye movement sleep
}

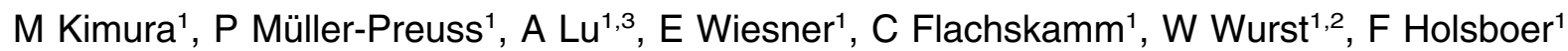 \\ and JM Deussing ${ }^{1}$
}

${ }^{1}$ Max Planck Institute of Psychiatry, Munich, Germany and ${ }^{2}$ Institute of Developmental Genetics, Helmholtz Zentrum München, German Research Center for Environmental Health, Neuherberg, Germany

\begin{abstract}
Impaired sleep and enhanced stress hormone secretion are the hallmarks of stress-related disorders, including major depression. The central neuropeptide, corticotropin-releasing hormone $(\mathrm{CRH})$, is a key hormone that regulates humoral and behavioral adaptation to stress. Its prolonged hypersecretion is believed to play a key role in the development and course of depressive symptoms, and is associated with sleep impairment. To investigate the specific effects of central CRH overexpression on sleep, we used conditional mouse mutants that overexpress CRH in the entire central nervous system (CRH-COE-Nes) or only in the forebrain, including limbic structures (CRH-COE-Cam). Compared with wild-type or control mice during baseline, both homozygous CRH-COE-Nes and -Cam mice showed constantly increased rapid eye movement (REM) sleep, whereas slightly suppressed non-REM sleep was detected only in CRH-COE-Nes mice during the light period. In response to 6-h sleep deprivation, elevated levels of REM sleep also became evident in heterozygous $\mathrm{CRH}-\mathrm{COE}-\mathrm{Nes}$ and -Cam mice during recovery, which was reversed by treatment with a CRH receptor type 1 (CRHR1) antagonist in heterozygous and homozygous CRH-COE-Nes mice. The peripheral stress hormone levels were not elevated at baseline, and even after sleep deprivation they were indistinguishable across genotypes. As the stress axis was not altered, sleep changes, in particular enhanced REM sleep, occurring in these models are most likely induced by the forebrain CRH through the activation of CRHR1. CRH hypersecretion in the forebrain seems to drive REM sleep, supporting the notion that enhanced REM sleep may serve as biomarker for clinical conditions associated with enhanced $\mathrm{CRH}$ secretion.

Molecular Psychiatry (2010) 15, 154-165; doi:10.1038/mp.2009.46; published online 19 May 2009
\end{abstract}

Keywords: corticotropin-releasing hormone; CRHR1 antagonist; REM sleep; depression; hypothalamic-pituitary-adrenocortical axis; sleep deprivation

\section{Introduction}

Corticotropin-releasing hormone (CRH) is a neuropeptide involved in the coordination of the humoral and behavioral response to stress. ${ }^{1-3}$ Prominent features of stress-elicited adaptations include increased anxiety, enhanced tension and arousal, as well as activation of the hypothalamic-pituitaryadrenocortical (HPA) axis.

Both the sleep-wake regulatory system and the HPA axis are intertwined, as administration of CRH,

Correspondence: Dr M Kimura, Neurogenetics of Sleep, Max Planck Institute of Psychiatry, Kraepelinstrasse 2 - 10, Munich D80804, Germany.

E-mail: kimura@mpipsykl.mpg.de

${ }^{3}$ Current address: National Institutes of Health, National Institute of Diabetes and Digestive and Kidney Diseases, Clinical Endocrinology Branch, Bethesda, MD 20892, USA.

Received 27 January 2009; accepted 13 April 2009; published online 19 May 2009 adrenocorticotropic hormone (ACTH) and corticosteroids produce distinct effects upon changes in vigilance states, detected by means of sleep electroencephalogram (EEG) in humans and animals. ${ }^{4-6}$ All these studies monitored the sleep EEG after acute or chronic treatment. For example, in healthy humans, repeated intravenous (i.v.) injections of $\mathrm{CRH}^{7}$ and continuous i.v. infusion of $\mathrm{ACTH}^{8}$ produced reductions of slow-wave sleep (SWS), correspondingly non-rapid eye movement (non-REM) sleep in rodents. Likewise, intracerebroventricular (i.c.v.) administration of $\mathrm{CRH}$ to rats resulted in enhanced wakefulness and suppression of non-REM sleep..$^{9,10}$ I.c.v.-injected ACTH ${ }^{11}$ and prolonged systemic infusion of corticosteroids ${ }^{12}$ in rats also decreased nonREM and REM sleep. These results suggest that the activation of the HPA axis contributes to wake responses under stress exposure. However, it remained unclear whether all the stress hormones acted on sleep directly or indirectly together, or separately 
through feedback action on CRH. Further, central administration of high dosages of CRH would give only an indirect reflection of stress-evoked CRH secretion.

To circumvent these problems, we used conditional mouse mutants in which overexpression of different $\mathrm{CRH}$ dosages is restricted to the central nervous system (CNS) or in a more confined manner to the anterior forebrain, including limbic structures. These mice do not show overt behavioral or endocrine abnormalities, for example, weight loss or hypercortisolism, under resting conditions, but respond with increased active stress-coping behavior and corticosterone release under stress conditions. ${ }^{13}$ Here, we could show that the significant contribution of the brain region-specific CRH to sleep is an enhancement of REM sleep that is independent from its capacity of HPA activation. Furthermore, we showed that the effects of CRH on sleep-wake control are mediated through the CRH type 1 receptors (CRHR1), as the administration of a specific CRHR1 antagonist reversed elevated REM sleep in mice conditionally overexpressing CRH (CRH-COE) during recovery after sleep deprivation (SD). Finally, we propose that the CRH-COE mouse line would be an ideal animal model to investigate the effect of spatially confined CRH hyperactivity and also aid to validate drug candidates targeting the central CRH system.

\section{Materials and methods}

\section{Animals}

A detailed description of the generation and characterization of conditional CRH-overexpressing mice has been described elsewhere. ${ }^{13}$ Briefly, CNS-restricted overexpression of CRH (CRH-COE-Nes) was achieved by breeding of $R 26^{\text {flopCrh/flop Crh }}$ (flop, floxed stop) mice to transgenic nestin (Nes)-Cre mice. ${ }^{14}$ For the forebrain-restricted overexpression of CRH in principal neurons (CRH-COE-Cam), R2 $6^{\text {flopCrh/flopCrh }}$ mice were crossed to transgenic Camk2a-Cre mice. ${ }^{15}$ In the $\mathrm{F}_{2}$ generation, we obtained $R 26^{+/+}$, R26 flopCrh/flopCrh,$\quad R 26^{+ \text {fllopCrh }}$ Nes-/Camk2a-Cre and R26 flopCrh/flopCrh Nes-/Camk2a-Cre mice, which we will refer to as CRH-COE ${ }^{\text {wt }}-\mathrm{Nes} /-\mathrm{Cam}$, CRH-COE ${ }^{\mathrm{con}}-\mathrm{Nes} /-$ Cam, CRH-COE ${ }^{\text {het }}$-Nes/-Cam and CRH-COE ${ }^{\text {hom-Nes/- }}$ Cam, respectively. Genotyping was carried out by PCR using primers: ROSA-1, 5'-AAAGTCGCTCTGAGTT GTTAT-3'; ROSA-5, 5' ${ }^{\prime}$ TAGAGCTGGTTCGTGGTGTG$3^{\prime}$; ROSA-6 5'-GCTGCATAAAACCCCAGATG-3' and ROSA-7, 5'-GGGGAACTTCCTGACTAGGG-3'. Standard PCR conditions resulted in a 398-bp wild-type and a 646-bp mutant PCR products. Animals with a premature deletion of the floxed transcriptional terminator sequence were identified by the occurrence of a 505-bp PCR product and were excluded from the studies. The presence of Nes- or Camk2a-Cre was evaluated using primers CRE-F, 5'-GATCGCTGC CAGGATATACG-3', CRE-R 5'-AATCGCCATCTTC CAGCAG-3', CTSQ-up 5'-ACAAGGTCTGTGAATCAT GC-3' and CTSQ-dn 5'-TTACAATGTGGATTTTG
TGGG-3' ${ }^{\prime}$, resulting in a Cre-specific PCR product of $574 \mathrm{bp}$ and a control PCR product of $1098 \mathrm{bp}$. CRHCOE-Nes mice were kept on a mixed 129S2/ $\mathrm{Sv} \times \mathrm{C} 57 \mathrm{BL} / 6 \mathrm{~J} \times \mathrm{SJL}$, and CRH-COE-Cam mice on a mixed $129 \mathrm{~S} 2 / \mathrm{Sv} \times \mathrm{C} 57 \mathrm{BL} / 6 \mathrm{~J} \times \mathrm{CBA} / \mathrm{J}$ background, at the breeding facility of the Max Planck Institute of Psychiatry. Male littermates, weighing 24-30 g (10-14-week-old) were used for the experiments. Around the occasion for surgery, animals were housed individually in a sound-attenuated recording chamber maintained at a regulated ambient temperature of $22 \pm 1{ }^{\circ} \mathrm{C}$ on a 12-h light/dark cycle (lights on at 0900 hours). The animals had access to water and food ad libitum. All animal studies were conducted according to the guidance of the European Community Council Directive, and experimental protocols were approved by the local commission for the Care and Use of Laboratory Animals of the State Government of Bavaria, Germany.

\section{Surgery}

The mice were anaesthetized with an intraperitoneal injection of a ketamine-xylazine mixture $(115 \mathrm{mg}$ and $11.5 \mathrm{mg} \mathrm{kg}^{-1}$, respectively) and chronically implanted with EEG and electromyographic (EMG) electrodes for polysomnographic recordings. The implant consisted of four stainless steel screws $(0.8 \mathrm{~mm}$ diameter) for EEG recordings that were placed through the skull epidur (coordinates, A $1.5 \mathrm{~mm}$ and $3 \mathrm{~mm}$; $\mathrm{L} \pm 1.7 \mathrm{~mm}$ each) and two gold wires inserted into the cervical portion of the trapezoid muscles for EMG recordings. All electrodes were soldered to a micro-socket affixed to the skull with dental acrylic resin. After surgery, the mice were allowed to spend ca. 10 days for recovery without cabling in the environment as mentioned above.

\section{Sleep recordings and data processing}

The lead wires of the EEG and EMG electrodes were connected to an electric swivel through a flexible tether. The weights of the swivel and tether were outbalanced through a mechanical device near to zero; thus the mice could move unrestrictedly and were acclimated for 3-4 days before the initiation of recording. EEG and EMG signals were amplified $(10000 \times)$, filtered (EEG $0.5-29 \mathrm{~Hz}, 48 \mathrm{~dB}$ per Oct.; EMG underwent root mean square rectification), and digitized by a high-speed analog-to-digital converter at a sampling rate of $64 \mathrm{~Hz}$. Then the signals were processed by a PC equipped with a LabVIEW program, especially designed for sleep EEG analysis (National Instruments, SEA Köln, Germany). Polygraphic data were all stored on a computer and processed offline later with the LabVIEW-based acquisition program, in which a Fast Fourier Transform (FFT) algorithm served for power spectrum analysis of particular EEG frequency contents, that is, $\delta(0.5-5 \mathrm{~Hz}), \theta(6-9 \mathrm{~Hz}), \alpha(10-15 \mathrm{~Hz})$ and $\beta$ $(16-29 \mathrm{~Hz})$. Using the aid of the FFT algorithm, adapted from a report by Louis et al., ${ }^{16}$ the spectral analysis was also undertaken to serve semiautomatic 
classification of the particular vigilance state as awake, non-REM sleep or REM sleep that were defined in 4-s epochs. Defined vigilance states were further confirmed visually and corrected if necessary. Summed power densities of slow-wave activity (SWA) during non-REM sleep were calculated between 0.5 and $4 \mathrm{~Hz}$ at a $0.5-\mathrm{Hz}$ bin and normalized by total EEG power. Epochs containing artifacts were eliminated from power spectral analysis.

Baseline recordings were initiated nearly 2 weeks after the animals had received surgical operation, and 24-h spontaneous sleep-wake patterns during baseline were compared among the different genotypes. Then, 6-h SD was applied from the beginning of the onset of the light period (at 0900 hours, that is, Zeitgeber time 0, ZT0) by gentle handling. During the SD period, examiners paid careful attention to the mice by playing with cotton swabs or tissue papers and so on, not to touch their body directly. Meantime, polygraphical recordings were continuously made, and we were able to cut off $97.5 \%$ of non-REM sleep and $100 \%$ of REM sleep on an average. Over the SD paradigm, differences in recovery sleep were evaluated among the genotypes.

\section{CRHR1 antagonist}

DMP696, generously provided by Bristol-Myers Squibb, was administered orally $1 \mathrm{~h}$ before the end of the SD session as a suspension in $0.25 \%$ methylcellulose at the dose of $30 \mathrm{mg} \mathrm{kg}^{-1}$. The dose and the timing of administration were chosen according to an earlier report, in which DMP696 blocks stressinduced ACTH secretion. ${ }^{17}$ The same animals received vehicle only $(0.25 \%$ methylcellulose in sterile water) as a control group on the other day at the same timing during SD. Drug volumes were $5 \mathrm{ml} \mathrm{kg}^{-1}$.

\section{Analyses of plasma corticosterone}

Baseline blood was withdrawn from the tail vein (ca. $20 \mu \mathrm{l})$ 5-6 days before performing SD with the same timing either equivalent to the end of 6-h SD (ZT6) or $6 \mathrm{~h}$ after SD (ZT12). On the day of SD, the same animals were killed at ZT6 or ZT12, and trunk blood was collected for further hormonal analyses. After collection, these blood samples were immediately separated into plasma and red blood cells by centrifugation for $15 \mathrm{~min}$ at 4000 c.p.m. at $4{ }^{\circ} \mathrm{C}$. Plasma levels of corticosterone were measured using a radioimmunoassay (RIA) kit (MP Biomedicals, Orangeburg, NY, USA). The sensitivity of the corticosterone RIA kit is $25 \mathrm{ng} \mathrm{ml}^{-1}$. The intra-assay and inter-assay coefficients of variation were $<12 \%$ for corticosterone.

\section{In situ hybridization}

The brain-specific overexpression of CRH in CRHCOE-Nes and CRH-COE-Cam mice was verified by quantitative in situ hybridization. Detailed procedures concerning in situ hybridization are provided in Supplementary Materials and Methods.

\section{Statistical analysis}

Time spent awake in non-REM and REM sleep was calculated in 1, 2, 12 or $24 \mathrm{~h}$ averages. Differences in sleep-wake patterns during baseline and recovery after SD were compared among different genotypes and statistically analyzed using either nonparametric two-way analysis of variance (ANOVA) (for 1 or $2 \mathrm{~h}$ averages) or one-way ANOVA (for 12 or $24 \mathrm{~h}$ averages). The effects of the CRHR1 antagonist on recovery sleep were evaluated in comparison between vehicle- and DMP696-treated days. The effects of SD on the levels of corticosterone were compared with the basal levels on a day without SD using nonparametric one-way ANOVA. If the $F$ values reached statistical significance, the Student-Newman-Keuls multiple comparison test was further applied for post hoc analysis. A level of $P<0.05$ was considered significant.

\section{Results}

CNS-specific overexpression of $\mathrm{CRH}$

Nes-Cre- and Camk2a-Cre-mediated excision of the transcriptional terminator resulted in overexpression of $\mathrm{CRH}$ from the R26 promotor and co-activation of the LacZ reporter gene (Supplementary Figure 1). The CNS- and forebrain-restricted overexpression of $\mathrm{CRH}$ in CRH-COE-Nes and CRH-COE-Cam mice, respectively, was confirmed by in situ hybridization and $\mathrm{X}$-Gal staining (Supplementary Figures 1B-H). As described earlier, ${ }^{13}$ only endogenous CRH expression was detected in the CNS of CRH-COE ${ }^{\text {wt }}$-Nes/-Cam and CRH-COE ${ }^{\text {con }}$-Nes/-Cam mice (Supplementary Figures 1B, C; data not shown). In CRH-COE ${ }^{\text {het }}$ and CRH$\mathrm{COE}^{\text {hom }}$-Nes mice, expression of exogenous $\mathrm{CRH}$, as well as of $L a c Z$, was detected throughout the brain and spinal cord, reflecting the CNS-restricted expression of Nes-Cre and the ubiquitous activity of the $R 26$ locus (Supplementary Figures 1F-H). In CRH-COE ${ }^{\text {het }}$

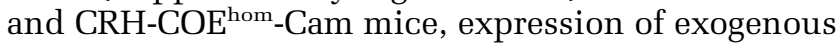
$\mathrm{CRH}$ was detected in the principal neurons of the limbic system, reflecting the predominantly forebrain-specific expression of Camk2a-Cre (Supplementary Figures 1D, E). Consistently higher CRH mRNA levels were detected in the brain sections of CRH-COE ${ }^{\text {hom }}$-Nes/-Cam mice (Supplementary Figures $1 \mathrm{E}, \mathrm{G})$ compared with CRH-COE ${ }^{\text {het }}$-Nes/-Cam animals (Supplementary Figures 1D, F), reflecting the gene dosage effect because of expression of exogenous CRH from a single or both $R 26$ alleles.

Sleep alteration in CNS-restricted CRH-COE-Nes mice Spontaneous sleep-wake patterns were monitored, and the baseline changes in their circadian dynamics

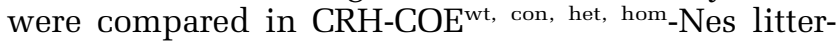
mates. All genotypes presented circadian-based variation for each vigilance state, showing a typical nocturnal sleep-wake behavior (Figure 1). CRH$\mathrm{COE}^{\mathrm{con}}$-Nes mice showed identical time-course changes in waking, non-REM sleep and REM sleep with those seen in CRH-COE ${ }^{\text {wt }}$-Nes mice (Figure 1, 


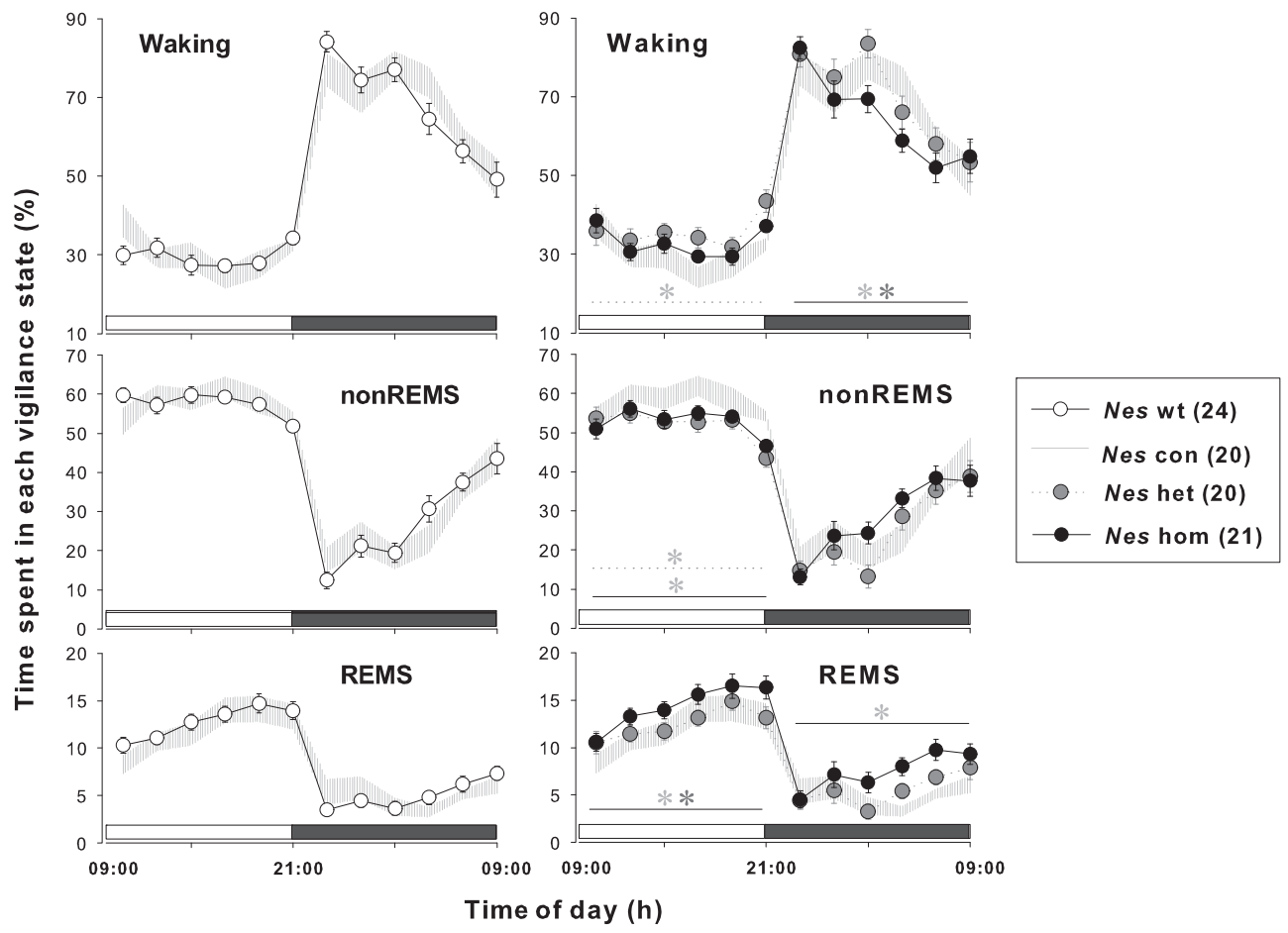

Figure 1 Time-course changes in sleep-wake patterns of corticotropin-releasing hormone (CRH)-COE-Nes mice. Data points \pm s.e.m. indicate $2 \mathrm{~h}$ averages in time spent in waking, non-rapid eye movement (non-REM) sleep (nonREMS) and REM sleep (REMS) during a baseline recording day: open circles, CRH-COE ${ }^{\mathrm{wt}}-\mathrm{Nes}(\mathrm{wt}), n=24$; hatched area, $\mathrm{CRH}_{-\mathrm{COE}}{ }^{\mathrm{con}}-\mathrm{Nes}(\mathrm{Nes}$ con), $n=20$; gray circles with dotted line, $\mathrm{CRH}_{-\mathrm{COE}}{ }^{\text {het }}$-Nes (Nes het), $n=20$; black circles with solid line, CRH-COE ${ }^{\text {hom }}$-Nes $(N e s$ hom), $n=21$. Horizontal open bar, light period; horizontal filled bar, dark period. Two-way analysis of variance (ANOVA) among four genotypes; for waking during the light period $F(3,246)=3.13, P<0.05$, during the dark period $F(3,246)=3.01$, $P<0.05$; for non-REM sleep during the light period $\mathrm{F}(3,246)=5.14, P<0.01$, during the dark period $\mathrm{F}(3,246)=1.71$, n.s., for REM sleep during the light period $\mathrm{F}(3,246)=4.32, P<0.01$, during the dark period $\mathrm{F}(3,246)=9.27, P<0.001$. No statistical significances were found in vigilance between wild-type and control mice (left panels). Heterozygous and homozygous mice showed significant differences in between or compared with con mice, indicated by its respective line and * (right panels).

left). However, in CRH-COE ${ }^{\text {het }}$-Nes and CRH-COE ${ }^{\text {hom }}$ Nes mice the amount and distribution of sleep and wakefulness differed from wild-type and control CRH-COE-Nes mice (Figure 1, Table 1). CRH-COE ${ }^{\text {het }}$ Nes mice had elevated wakefulness during the light

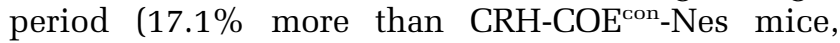
$P<0.05)$, whereas non-REM sleep was diminished in return $\left(10.3 \%\right.$ less than CRH-COE ${ }^{\text {con }}-N e s$ mice, $P<0.05$ ) (Figure 1, right and Table 1). Although an increase in waking time during the light period was not statistically evident $(7.9 \%$ more than CRH$\mathrm{COE}^{\mathrm{con}}-$ Nes mice, $P>0.05$ ), $\mathrm{CRH}-\mathrm{COE}^{\mathrm{hom}}-$ Nes showed significantly reduced non-REM sleep around the same period as $\mathrm{CRH}-\mathrm{COE}^{\text {het }}$-Nes animals $(8.8 \%$ less than CRH-COE ${ }^{\mathrm{con}}$-Nes mice, $\left.P<0.05\right)$. On the contrary, REM sleep was markedly enhanced during light and dark periods regarding bihourly distribution (Figure 1, right), whereas the cumulative amount of REM sleep in either the light period or total 24-h recording time did not reach the significance level (19.8 and $29.4 \%$ more than CRH-COE ${ }^{\text {con }}$-Nes mice, respectively, $P>0.05$, Table 1). While the level of REM sleep was upregulated in the dark period (52.4\% more than CRH-COE ${ }^{\text {con }}$-Nes mice, $\left.P<0.05\right)$, the amount of wakefulness was attenuated $(5.4 \%$ less than CRH-COE ${ }^{\mathrm{con}}$-Nes mice, $P<0.05$, Figure 1, right). Although CRH-COE ${ }^{\text {het }}$-Nes mice did not show any significant increases in REM sleep, the amount of REM sleep occupying total sleep time tended to be higher than in wild-type and control CRH-COE-Nes mice (Table 1). Across the four genotypes such REM sleep ratio was highest in CRH-COE ${ }^{\text {hom }}$-Nes mice $(P<0.05)$, in which disparities in the ratios between the light and dark period found in control mice disappeared.

\section{$S D$ triggers more REM sleep during recovery in CRH-COE-Nes mice}

Six-h SD made a significant effect on the disparity of sleep phenotypes in CRH-COE-Nes mice that had already been seen during baseline recording. The comparison of sleep patterns after SD showed that CRH-COE ${ }^{\text {hom }}$-Nes mice spent less time in non-REM sleep than $\mathrm{CRH}-\mathrm{COE}^{\mathrm{con}}$-Nes animals $(9.5 \%$ less than control during ZT6-12, $P<0.05$, Figure 2). Although CRH-COE ${ }^{\text {het }}$-Nes mice showed a lower amount of spontaneous non-REM sleep as mentioned earlier, the rebound of non-REM sleep after SD was similar to that seen in CRH-COE ${ }^{\text {con }}$-Nes mice. In contrast, REM sleep changes were dynamic; CRH-COE ${ }^{\text {het }}$-Nes and 
Table 1 Sleep time during the baseline recording

\begin{tabular}{|c|c|c|c|c|c|c|c|c|c|}
\hline \multirow[t]{2}{*}{ Genotype } & \multirow[b]{2}{*}{$N$} & \multicolumn{3}{|c|}{ nonREMS (min) } & \multicolumn{3}{|c|}{ REMS (min) } & \multicolumn{2}{|c|}{ REMS ratio (\%) } \\
\hline & & 12-h light & 12-h dark & $24 h$ & 12-h light & 12-h dark & $24 h$ & 12-h light & 12-h dark \\
\hline CRH-COE ${ }^{\mathrm{wt}}-\mathrm{Nes}$ & 24 & $414.1 \pm 6.3$ & $197.6 \pm 10.4$ & $611.7 \pm 12.3$ & $91.7 \pm 4.8$ & $35.9 \pm 3.9$ & $127.5 \pm 7.6$ & $18.1 \pm 0.9$ & $14.6 \pm 1.0$ \\
\hline CRH-COE ${ }^{\mathrm{con}}-\mathrm{Nes}$ & 20 & $415.6 \pm 10.3$ & $194.7 \pm 12.4$ & $610.3 \pm 19.0$ & $86.3 \pm 7.2$ & $35.5 \pm 4.5$ & $121.7 \pm 10.5$ & $17.1 \pm 1.4$ & $15.1 \pm 1.5$ \\
\hline CRH-COE ${ }^{\text {het }}$-Nes & 20 & $372.9 \pm 13.3$ ** & $178.0 \pm 14.5$ & $552.8 \pm 21.9$ & $89.7 \pm 5.8$ & $40.0 \pm 5.6$ & $129.8 \pm 10.4$ & $19.5 \pm 1.1$ & $17.1 \pm 1.4$ \\
\hline $\mathrm{CRH}-\mathrm{COE}^{\mathrm{hom}}$-Nes & 21 & $379.2 \pm 9.0^{* *}$ & $205.6 \pm 10.5$ & $584.2 \pm 15.0$ & $103.4 \pm 5.9$ & $54.1 \pm 5.6^{* * *}$ & $157.5 \pm 10.2$ & $21.5 \pm 1.2^{*}$ & $20.6 \pm 1.6^{* *}$ \\
\hline \multicolumn{10}{|l|}{ One-way ANOVA } \\
\hline$P$-value & & 0.002 & 0.439 & 0.058 & 0.209 & 0.028 & 0.050 & 0.047 & 0.010 \\
\hline CRH-COE ${ }^{\mathrm{con}}$-Cam & 9 & $430.0 \pm 13.7$ & $188.7 \pm 21.3$ & $618.4 \pm 26.6$ & $69.4 \pm 7.9$ & $25.0 \pm 5.8$ & $94.4 \pm 10.0$ & $13.9 \pm 1.5$ & $10.9 \pm 1.5$ \\
\hline CRH-COE ${ }^{\text {het }}$-Cam & 10 & $404.1 \pm 10.0$ & $221.6 \pm 25.3$ & $625.7 \pm 28.7$ & $72.6 \pm 6.9$ & $32.9 \pm 5.2$ & $105.5 \pm 9.0$ & $15.2 \pm 1.4$ & $12.8 \pm 1.3$ \\
\hline CRH-COE ${ }^{\text {hom }}$-Cam & 11 & $397.4 \pm 9.2$ & $228.6 \pm 17.6$ & $626.0 \pm 16.0$ & $84.5 \pm 6.0$ & $36.6 \pm 5.5$ & $121.1 \pm 8.5$ & $17.5 \pm 1.1$ & $13.2 \pm 1.1$ \\
\hline \multicolumn{10}{|l|}{ One-way ANOVA } \\
\hline$P$-value & & 0.109 & 0.402 & 0.970 & 0.269 & 0.345 & 0.133 & 0.165 & 0.430 \\
\hline
\end{tabular}

Abbreviations: CRH, corticotropin-releasing hormone; nonREMS, non-rapid eye movement sleep; REMS, rapid eye movement sleep.

Values are means \pm s.e.m. REMS ratio was calculated as per cent REM sleep in total sleep.

Statistical significances are indicated with asterisks relative to average of CRH-COE ${ }^{\text {con }}-\mathrm{Nes}$ only $\left({ }^{*}\right)$, both $\mathrm{CRH}^{-\mathrm{COE}}{ }^{\mathrm{wt}}-\mathrm{Nes}$ and CRH-COE ${ }^{\text {con }}-$ Nes $(* *)$, or all the other genotypes $(* * *)$, analyzed using one-way analysis of variance (ANOVA) with the Student-Newman-Keuls multiple comparison test $(P<0.05)$. In the genotype of $\mathrm{CRH}-\mathrm{COE}^{\mathrm{con}}$-Cam, no statistical differences in summarized baseline data were found by one-way ANOVA.

CRH-COE hom $_{\text {-Nes }}$ mice displayed highly elevated REM sleep in response to SD $(44.9 \%$ (het) and $39.4 \%$ (hom) more than controls during ZT6-12, $P<0.05$, Figure 2). During the dark period, REM sleep in CRH-COE ${ }^{\text {hom }}$-Nes mice remained elevated, but increased REM sleep compared with other genotypes had been observed already during baseline recording. Therefore, changes in nocturnal sleep time were not really affected by SD, and the rebound in recovery sleep triggered by SD was mostly detected during post-SD hours 6-12 (ZT6-12). Although the distribution of that rebound sleep differed in a genotypedependent manner, the peak appearance of rebound sleep was the same in both cases in non-REM sleep (between ZT8-10) and REM sleep (between ZT10-12).

The forebrain-restricted CRH-COE-Cam mice also show enhanced REM sleep

Spontaneous sleep-wake patterns between wild-type and control CRH-COE-Nes mice were indistinguishable. Therefore, wild-type mice were omitted when monitoring sleep EEGs from COE-Cam mice. As

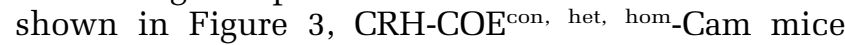
also showed nocturnal sleep-wake activities. During the baseline recording, time-course changes in nonREM sleep were not significantly different from all three genotypes in both light and dark periods (Figure 3). In contrast, elevated appearance of REM sleep was demonstrated over the bihourly distribution in CRH$\mathrm{COE}^{\mathrm{hom}}$-Cam mice. Significant differences in REM sleep amounts were found between CRH-COE ${ }^{\text {hom }}$-Cam and $\mathrm{CRH}-\mathrm{COE}^{\mathrm{con}, \text { het }}-\mathrm{Cam}$ mice during the light period, and CRH-COE ${ }^{\text {con }}$-Cam mice during the dark period (Figure 3). However, the increased level of REM sleep failed to mark significance when calculated into either 12 -h $(21.6 \%$ more during the light period and $46.5 \%$ more during the dark period than CRH-COE ${ }^{\text {con }}$-Cam mice, $\left.P>0.05\right)$ or 24 -h $(28.3 \%$ more than CRH-COE ${ }^{\mathrm{con}}$-Cam mice, $\left.P>0.05\right)$ cumulative summary (Table 1). REM sleep ratios versus total sleep tended to show higher values in CRH-

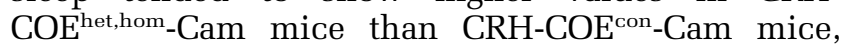
but the differences were not as large as in CRHCOE-Nes mice (Table 1).

After baseline recording, all CRH-COE-Cam mice were subjected to 6-h SD in succession (Figure 3), and their recovery sleep was compared across each genotype. Unlike in CRH-COE-Nes mice, non-REM sleep responses after SD in CRH-COE-Cam mice were similar in all genotypes. The peak appearance of nonREM sleep was observed between ZT6-8, which occurred earlier in CRH-COE-Cam mice than in CRH-COE-Nes mice in response to SD. On the contrary, elevated REM sleep after SD appeared in both CRH-COE ${ }^{\text {het,hom }}$-Cam mice similar to CRH-

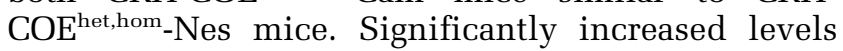
of REM sleep were shown throughout the post-SD hours 6-24 (ZT6-24), in which CRH-COE het,hom - Cam mice spent 26.0 and $33.9 \%$, respectively, more than CRH-COE ${ }^{\text {con }}$-Cam mice during the entire SD day (Figure 3). As elevated REM sleep in CRH-COE ${ }^{\text {hom }}$ Cam mice was already observed on the baseline day, the level of REM sleep after SD in CRH-COE ${ }^{\text {hom }}$-Cam mice was not particularly enhanced by SD. However, in the case of in CRH-COE ${ }^{\text {het }}$-Cam mice, SD triggered 


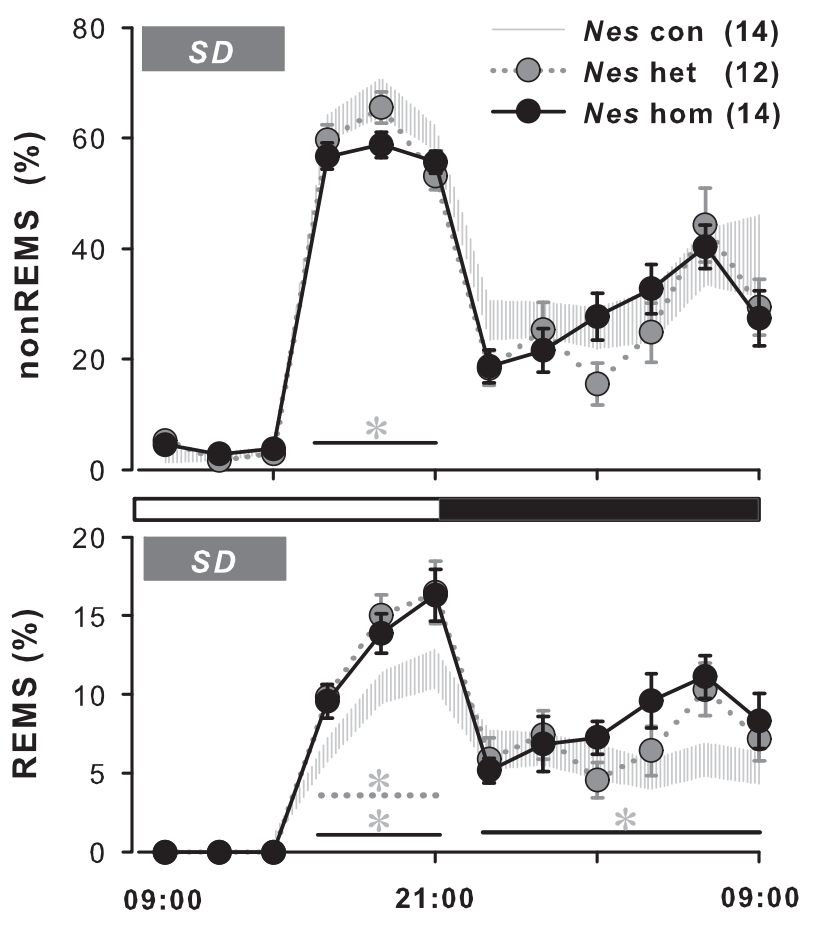

Time of Day (h)

Figure 2 Changes in sleep patterns after sleep deprivation in corticotropin-releasing hormone (CRH)-COE-Nes mice. Data points \pm s.e.m. indicate $2 \mathrm{~h}$ averages in time spent in non-rapid eye movement (non-REM) sleep (nonREMS) and REM sleep (REMS). Sleep deprivation (SD) was performed for $6 \mathrm{~h}$ from the beginning of the onset of the light period (Zeitgeber time 0, ZT0), indicated by a gray bar. Hatched

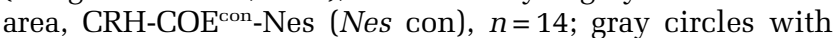
dotted line, CRH-COE ${ }^{\text {het }}$-Nes (Nes het), $n=12$; black circles with solid line, CRH-COE ${ }^{\text {hom }}$-Nes (Nes hom), $n=14$. Horizontal open bar, light period; horizontal filled bar, dark period. Two-way analysis of variance among three genotypes; for non-REM sleep during post-SD hours 6-12 (ZT612 ) in the light period $F(2,111)=4.13, P<0.05$, for $R E M$ sleep during ZT6-12 in the light period $F(2,111)=9.55$, $P<0.001$, during the 12 -h dark period $\mathrm{F}(2,222)=4.16$, $P<0.05$. No statistical significances were found in recovery sleep between wild-type and control mice (data not shown). Heterozygous and/or homozygous mice showed significant differences compared with con mice, indicated by its respective line and *.

REM sleep enhancement. The recovery of REM sleep reached the peak level at ZT8-10 in CRH-COE ${ }^{\text {het }}$-Cam

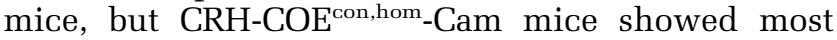
elevated REM sleep between ZT10-11.

\section{The HPA axis is intact in both CRH-COE-Nes and CRH-COE-Cam mice}

In a naive group of animals, plasma levels of corticosterone were compared before and after SD to determine whether sleep time loss affects HPA activity. On the day of SD, the trunk blood was taken immediately after the end of SD (ZT6) and $6 \mathrm{~h}$ later (ZT12). Beforehand, the baseline blood was collected at ZT6 and ZT12. No differences in basal levels of plasma corticosterone were found across all genotypes at neither ZT6 nor ZT12 in both CRH-COE-Nes and CRH-COE-Cam mice, as we reported earlier (Figure 4, upper panels). ${ }^{13}$ As it is known that the corticosterone levels naturally increase toward the dark period, the levels of plasma corticosterone at ZT12 were higher than those at ZT6 in all genotypes of CRH-COE-Nes and CRH-COE-Cam mice, although CRH-COE ${ }^{\text {het,hom }}$-Cam mice did not show statistical difference. On the day of SD, plasma levels of corticosterone at ZT6 and ZT12 did not differ among genotypes as baseline. However, increases in the plasma corticosterone levels after SD at ZT6 were significantly greater in control mice than in the other mice that had elevated the brain CRH concentrations, that is, $\mathrm{CRH}-\mathrm{COE}^{\mathrm{wt}}$-Nes (3.7 times more, $\left.P<0.01\right)$ and CRH-COE ${ }^{\text {con }}$-Nes mice $(3.4$ times more, $P<0.01)$ versus CRH-COE ${ }^{\text {het }}$-Nes $(2.8$ times more, $P<0.05)$ and $\mathrm{CRH}-\mathrm{COE}^{\mathrm{hom}}-\mathrm{Nes}$ mice $(2.0$ times more, $P<0.05$, Figure 4, left); $\mathrm{CRH}-\mathrm{COE}^{\mathrm{con}}$-Cam mice (3.2 times more, $P<0.01$ ) versus $\mathrm{CRH}-\mathrm{COE}^{\text {het }}$-Cam (1.6 times more, $P>0.05$ ) and $\mathrm{CRH}-\mathrm{COE}^{\text {hom }}$-Cam mice (1.5 times more, $P>0.05$, Figure 4 , right).

Antagonizing CRHR1 normalizes enhanced REM sleep after $S D$ in $C R H$-COE-Nes mice

To examine whether overproduced CRH signaling through CRHR1 is responsible for sleep alterations, especially increases in REM sleep occurring after SD, we tested a CRHR1 antagonist, DMP696, during SD and subsequently compared sleep patterns of DMP696- and vehicle-treated animals. In CRH$\mathrm{COE}^{\mathrm{wt}}$-Nes mice, DMP696 did not exert any effects on recovery sleep. However, in CRH-COE ${ }^{\text {con }}-\mathrm{Nes}$ mice, DMP696 treatment affected the hourly distribution of REM sleep, but not of non-REM sleep (Figure 5), showing a slight REM sleep attenuating effect of the antagonist (Table 2). Such normalizing effects on sleep were seen more clearly in heterozygous and homozygous CRH-COE-Nes mice. DMP696 dramatically reduced SD-elicited REM sleep enhancement in CRH-COE ${ }^{\text {het }}$-Nes and CRH-COE ${ }^{\text {hom }}$ Nes mice. The level of hourly non-REM sleep remained significantly elevated in both $\mathrm{CRH}-\mathrm{COE}^{\text {het }}$ Nes and CRH-COE ${ }^{\text {hom-Nes }}$ mice under DMP696 (Figure 5). After DMP696 treatment, differences in REM sleep ratios among the four genotypes were smaller than after vehicle treatment, indicating that antagonizing CRHR1 normalized an imbalance of REM sleep occurrence in CRH-COE-Nes mice (Table 2).

CRH overexpression affects slow-wave activity

The amplitude or power of SWA expresses the depth of non-REM sleep, indicating a reflection of accumulated sleep demand as explained in the two-process model. ${ }^{18}$ It is well documented that increased power spectra of SWA are detected during non-REM sleep after prolonged wakefulness such as SD. ${ }^{19}$ In all CRH-COE-Nes mice, the magnitude of SWA was higher at the beginning than at the end of the light 


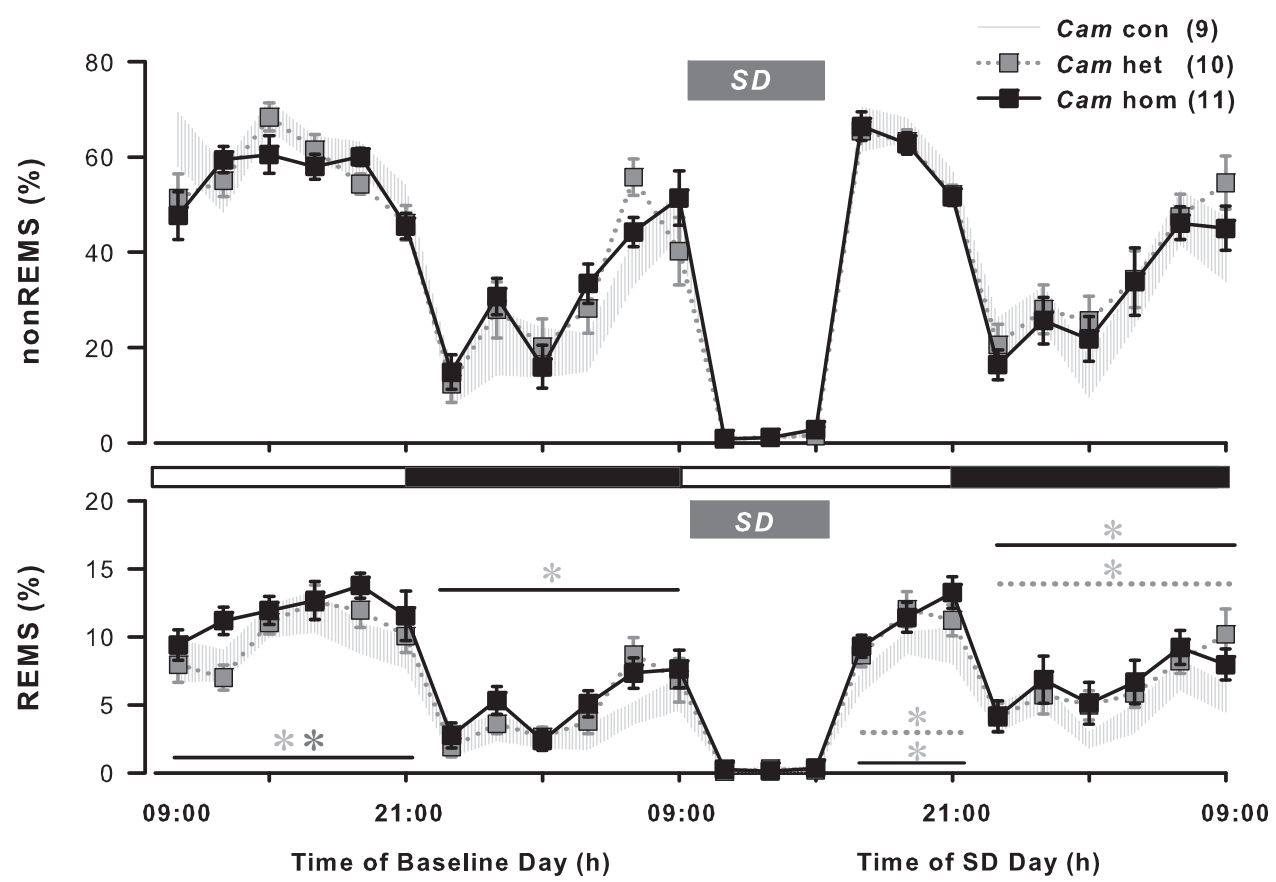

Figure 3 Sleep distributions in corticotropin-releasing hormone (CRH)-COE-Cam mice during baseline and after sleep deprivation. Data points \pm s.e.m. indicate $2 \mathrm{~h}$ averages in time spent in non-rapid eye movement (non-REM) sleep (nonREMS) and REM sleep (REMS). Sleep deprivation (SD) was performed for $6 \mathrm{~h}$ from the onset of the light period (Zeitgeber time 0 , ZT0), indicated by a gray bar, following the baseline recording. Hatched area, CRH-COE ${ }^{\text {con }}-$ Cam (Cam con), $n=9$; gray squares with dotted line, CRH-COE ${ }^{\text {het }}$-Cam (Cam het), $n=10$; black squares with solid line, CRH-COE ${ }^{\text {hom }}-C^{-C m}(C a m$ hom), $n=11$. Horizontal open bar, light period; horizontal filled bar, dark period. Two-way analysis of variance among three genotypes; on baseline day for REM sleep during the light period $\mathrm{F}(2,162)=4.47, P<0.05$, during the dark period $\mathrm{F}(2,162)=3.34, P<0.05$; on SD day for REM sleep during ZT6-12 in the light period $\mathrm{F}(2,81)=7.94, P<0.001$, during the 12 -h dark period $\mathrm{F}(2$, $162)=3.33, P<0.05$. No statistical significances were found in respect to non-REM sleep on both days across all genotypes. Heterozygous and/or homozygous mice showed significant differences compared with con mice, indicated by its respective line and *.

period during baseline and reached the highest value after termination of SD (Supplementary Figure 2). However, CRH-COE ${ }^{\text {het }}$-Nes mice at baseline showed a relatively blunted distribution of SWA and its levels were lowest when compared with those of the other genotypes (Supplementary Figure 2, $P<0.01$ ), whereas effects of SD on elevated levels of SWA were not distinguishable across all the three genotypes. During the dark period, CRH-COE ${ }^{\text {het, hom}}$-Nes mice showed lower power spectrum compared with CRH$\mathrm{COE}^{\mathrm{con}}$-Nes mice, but the following night after SD, the power between the three genotypes was not significantly different (Supplementary Figure 2). With the treatment of DMP696, elevated SWA after SD was not significantly affected in all genotypes, and changes in the levels of SWA power stayed similar as seen on the day without treatment (data not shown).

\section{Discussion}

Conditional transgenic mouse lines overexpressing $\mathrm{CRH}$ in the brain and specific areas of the brain allowed us to unravel the role of CRH in sleep-wake regulation. Earlier attempts were hampered by interference of the peripheral stress hormones that also affect sleep. For example, central administration of CRH to rats, which elicits increased plasma ACTH and corticosterone concentrations, affects sleep directly or even through interactions with immunomodulators. ${ }^{9,10,20}$ Also, conventional CRH-overexpressing mice hypersecrete corticosterone ${ }^{21}$ and develop a Cushing-like phenotype, ${ }^{22}$ thus limiting their usefulness for studies of sleep physiology. Finally, CRH receptor antagonists often failed to provide further insight into the role of CRH in sleep, ${ }^{10,23-25}$ as $\mathrm{CRH}$ is secreted in pathophysiologically relevant amounts only if homeostasis is disturbed, rendering $\mathrm{CRH}$ receptor antagonists under resting conditions ineffective.

Many complex mental diseases, including depression and anxiety disorders, can be initiated by inadequate adaptation to stress. ${ }^{26}$ Specifically, prolonged central secretion of CRH is believed to account for a number of signs and symptoms characterizing these disorders. ${ }^{27,28}$ Among these symptoms are manifold sleep disturbances, and polysomnographic recordings showed disinhibited REM sleep and a decrease of SWS. ${ }^{29,30}$ According to our transgenic mouse model, $\mathrm{CRH}$ accounts for these changes in sleep architecture. Both CRH-COE ${ }^{\text {hom }}-N e s$ and -Cam 

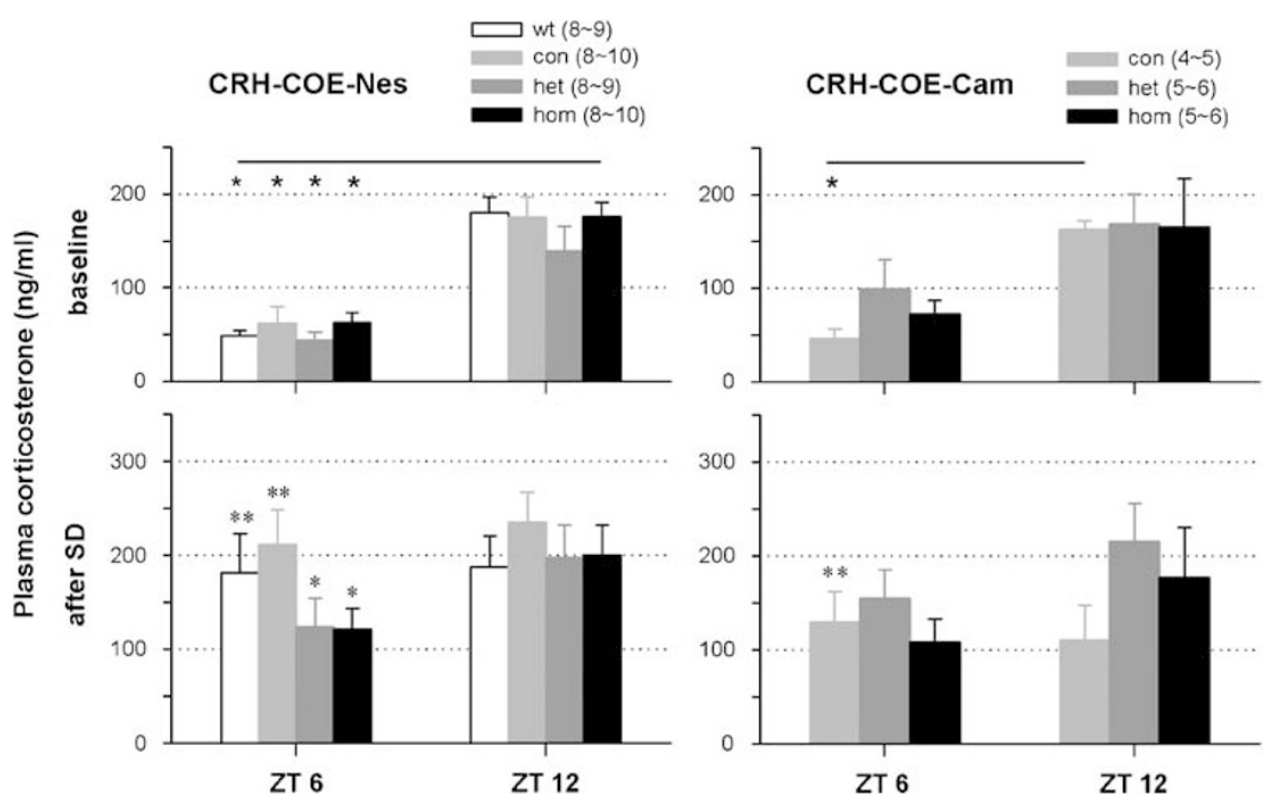

Figure 4 Effects of sleep deprivation (SD) on plasma levels of corticosterone in corticotropin-releasing hormone (CRH)COE-Nes and CRH-COE-Cam mice. Height \pm s.e.m. of columns indicates quantities of plasma corticosterone in the blood samples taken at Zeitgeber time (ZT)6 and 12 separately on baseline day and the day of SD from the same animals. White, CRH-COE ${ }^{\text {wt }}$-Nes (wt); light gray, CRH-COE ${ }^{\text {con }}$-Nes or CRH-COE ${ }^{\text {con }}-\mathrm{Cam}$ (con); dark gray, CRH-COE ${ }^{\text {het }}-\mathrm{Nes}_{\text {or }} \mathrm{CRH}_{-} \mathrm{COE}^{\text {het }}-\mathrm{Cam}$ (het); black, CRH-COE ${ }^{\text {hom }}$-Nes or CRH-COE ${ }^{\text {hom }}$-Cam (hom). Varied numbers of samples in parentheses were due to technical reasons. * indicates statistical differences in the values during baseline between ZT6 and ZT12, compared with each respective genotype $(P<0.05) .{ }^{*}$ denotes the statistical significance in elevated levels of plasma corticosterone after SD, compared with the respective baseline $\left({ }^{*} P<0.05,{ }^{*}{ }^{*} P<0.01\right)$.

\section{nonREMS}

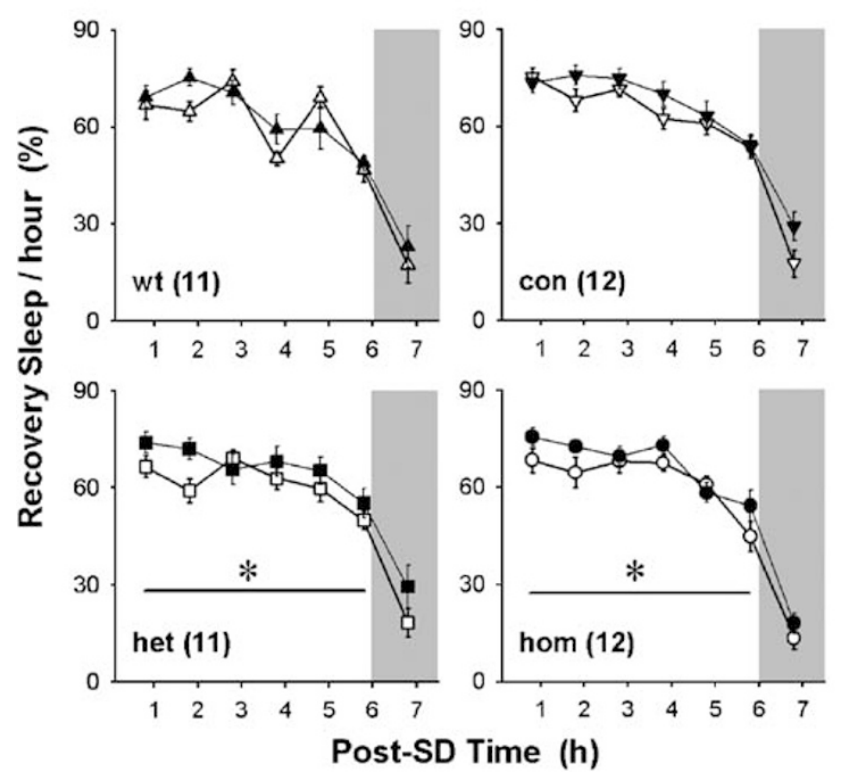

REMS

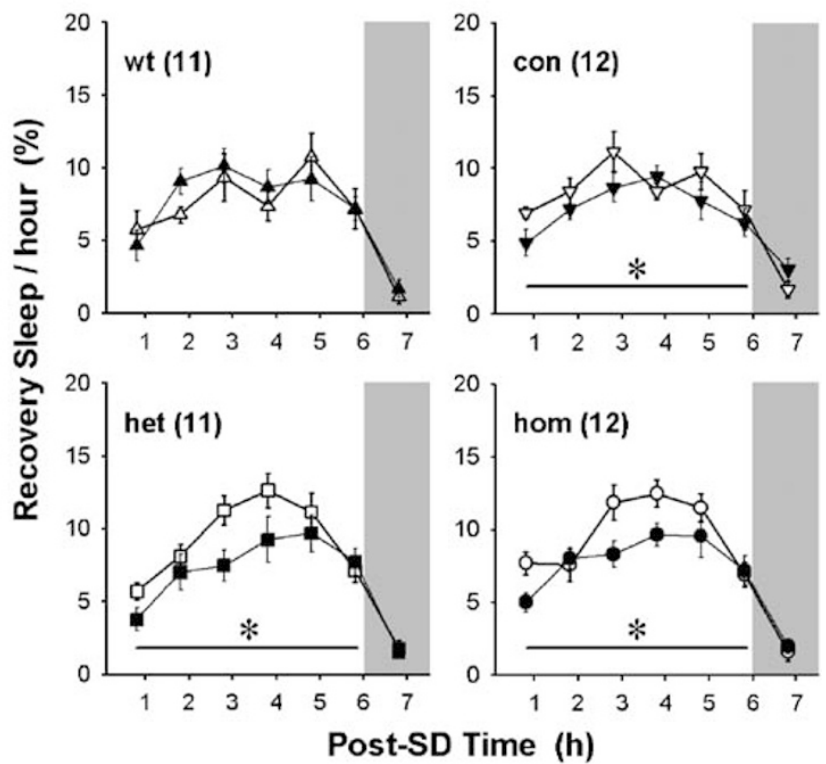

Figure 5 Effects of a corticotropin-releasing hormone receptor type 1 (CRHR1) antagonist, DMP696, on recovery sleep after sleep deprivation (SD) in CRH-COE-Nes mice. Data points \pm s.e.m. indicate $1 \mathrm{~h}$ averages in time spent in non-rapid eye movement (non-REM) sleep (nonREMS) and REM sleep (REMS) during $7 \mathrm{~h}$ after 6-h SD initiated at Zeitgeber time (ZT)0. Animals received either vehicle or DMP696 per os at ZT5, at $1 \mathrm{~h}$ before the end of SD. Open and filled symbols indicate sleep changes after vehicle and antagonist treatment, respectively. Shaded area indicates the dark period. Numbers in brackets represent the sample size. Two-way analysis of variance for treatment effect between each genotype; $\mathrm{CRH}^{-\mathrm{COE}^{\mathrm{con}}-\mathrm{Nes} \text { for }}$ REM sleep $F(1,132)=4.55, P<0.05$; CRH-COE ${ }^{\text {het }}$-Nes for non-REM sleep $F(1,120)=5.68, P<0.05$, for REM sleep $F(1$, $120)=8.19, P<0.01$; CRH-COE ${ }^{\text {hom }}$-Nes for non-REM sleep $\mathrm{F}(1,132)=5.90, P<0.05$, for $\mathrm{REM}$ sleep $\mathrm{F}(1,132)=8.62, P<0.01$.

* denotes statistical significance in treatment $(P<0.05)$. 
Table 2 Effects of CRH receptor type 1 antagonist on recovery sleep after 6-h sleep deprivation

\begin{tabular}{|c|c|c|c|c|c|}
\hline \multirow[b]{2}{*}{ Genotype } & \multirow[b]{2}{*}{$N$} & \multicolumn{2}{|c|}{ Difference Ant.-Veh. (\%) } & \multicolumn{2}{|c|}{ REMS ratio (\%) } \\
\hline & & nonREMS & REMS & Veh & Ant \\
\hline CRH-COE ${ }^{\mathrm{wt}}$-Nes & 11 & $102.9 \pm 3.0$ & $103.6 \pm 9.3$ & $11.2 \pm 1.0$ & $11.3 \pm 0.9$ \\
\hline CRH-COE ${ }^{\text {con }}-\mathrm{Nes}$ & 12 & $104.9 \pm 2.0$ & $85.2 \pm 6.2$ & $11.7 \pm 0.9$ & $9.7 \pm 0.7$ \\
\hline CRH-COE ${ }^{\text {het }}$-Nes & 11 & $109.0 \pm 3.9$ & $80.2 \pm 8.2^{*}$ & $13.3 \pm 0.4$ & $10.3 \pm 1.0^{*}$ \\
\hline CRH-COE ${ }^{\text {hom }}-\mathrm{Nes}$ & 12 & $107.8 \pm 2.4^{*}$ & $82.2 \pm 4.2^{*}$ & $13.5 \pm 0.8$ & $10.6 \pm 0.6^{*}$ \\
\hline \multicolumn{6}{|l|}{ One-way ANOVA } \\
\hline$P$-value & & 1.000 & 0.101 & 0.134 & 0.601 \\
\hline
\end{tabular}

Abbreviations: Ant., antagonist DMP696; CRH, corticotropin-releasing hormone; nonREMS, non-rapid eye movement sleep; REMS, rapid eye movement sleep; Veh., vehicle.

Values are means \pm s.e.m. for $6 \mathrm{~h}$ during the light period after 6 -h sleep deprivation.

Differences were relative values in percentile of sleep amount on a day of antagonist treatment compared with average on another day of vehicle treatment set as $100 \%$. REMS ratio was calculated as per cent REM sleep in 6-h total recovery sleep. * Statistical differences from average of corresponding vehicle groups, analyzed by paired $t$-test $(P<0.05)$. One-way analysis of variance shows no statistical significance among genotypes.

mice exhibited constantly elevated REM-sleep levels. Heterozygous animals of both mouse lines, which have only moderately increased brain CRH levels in respective brain regions, showed similarly elevated REM sleep in response to forced awakening during recovery after SD.

As reported by $\mathrm{Lu}$ et al., ${ }^{13}$ our conditional CRH overexpressing mice, that is, heterozygous and homozygous CRH-COE-Nes mice in which the entire brain is exposed to an overexpression of CRH, show unaffected plasma ACTH and corticosterone concentrations in the morning as well as in the evening. Accordingly, we failed to observe significant differences in those stress hormone levels between different genotypes at baseline and even after SD, although restrained stress elicits the stress hormone release in the CRH-COE ${ }^{\text {het,hom}}$-Nes mice compared with those in control littermates. ${ }^{13}$ CRH-COE mice do not seem to recognize sleep loss as a stressor, and undisturbed HPA axis activity in CRH-COE-Nes and -Cam mice implies that overexpressed CRH acts only centrally, not provoking systemic endocrine activity reflected by plasma ACTH and corticosterone concentrations. Thus, this genetic mouse model is a suitable tool to understand the mechanism and function of $\mathrm{CRH}$ within the brain.

The sleep phenotype of enhanced REM sleep is also present when CRH overexpression is restricted more specifically within the forebrain. In the CRH-COECam mice, CRH is overexpressed only in the limited brain areas including limbic structures, such as the amygdala, implicated in emotional responses. ${ }^{31}$ It is well known that emotions and REM sleep are closely related. There is a major projection of CRH pathways from the amygdala to pontine areas, ${ }^{32,33}$ where REMon cells are dominant in the cholinergic system. ${ }^{34}$ $\mathrm{CRH}$ is capable of activating these areas to induce muscle atonia that is one of the characteristics accompanying REM sleep..$^{35}$ When the amygdala receives either electric stimulation or cholinergic activation, prolonged REM sleep occurs. ${ }^{36,37}$ Further, $\mathrm{CRH}$ infusion into the central nucleus of the amygdala (CeA) induces c-Fos expression in the pontine cholinergic neurons. ${ }^{38}$ Accumulated evidence would support that a mechanism of enhanced REM sleep in CRH-COE-Cam mice underlies amygdaloid CRH and pontine cholinergic interaction. As the amygdaloid circuit plays an important role in the regulation of REM sleep, ${ }^{39-41}$ stress-induced CRH release from the limbic system plausibly contributes to REM sleep alteration through this. ${ }^{42}$

Unexpectedly, CRH-COE mice did not show a stereotype of insomnia. Through clinical observation and data from animal experiments, we suspected that elevated levels of CRH in the brain would have suppressed non-REM sleep or increased waking time. ${ }^{6,9,10}$ In contrast, after SD the orally given CRHR1 antagonist increased non-REM sleep in both heterozygous and homozygous CRH-COE-Nes mice, which implies that under stressful conditions, such as SD, the brain CRH is also involved in non-REM sleep disturbances through CRHR1. ${ }^{43}$ There is no remarkable effect of the CRHR1 antagonist in control animals, in which central CRH excess is limited, and thus rendering receptor blockade of no avail. From these observations, we conclude that the CRHR1 antagonist treatment could be of use to restore impaired sleep patterns only if CRH stimulation occurs in a pathophysiological range, such as severe acute or chronic stress, rather than under normal circumstances. ${ }^{44}$ In this study, the CRHR1 antagonist affected REM but not non-REM sleep response to SD in $\mathrm{CRH}-\mathrm{COE}^{\mathrm{con}}$-Nes mice. Apparently, REM sleep is a fragile state and receives a more dominant influence than non-REM sleep when CRH is excessively produced in particular parts of the brain. ${ }^{23,45}$ The results from the CRHR1 antagonist treatment in this model underscore potential effects of central CRH on sleep through CRHR1, as CRH induces REM sleep and attenuates non-REM sleep. ${ }^{20}$ 
The CRH-COE mouse lines can be regarded as an animal model that allows to study central hypersecretion of CRH, which is hypothesized to be a key factor in causality of depression. ${ }^{28}$ The genetic engineering strategy used here allows stable and chronic overexpression of $\mathrm{CRH}$ in the brain ${ }^{13}$ which makes us capable of experimentally mimicking some aspects observed in the clinical situation. ${ }^{46-48}$ In this model, the HPA axis is undisturbed under basal conditions, which does not apply to the cases of stress models accomplished from selectively bred or genetically vulnerable strains. ${ }^{49}$ Also patients who are recovered from depression but still carry vulnerability to further disease episodes have near normal HPA axis activity though symptom-free. ${ }^{26}$ On the other hand, central $\mathrm{CRH}$ hypersecretion is not necessarily reflected by the peripheral stress hormone excess, as clinical response to CRHR1 antagonists in depression is not straightforwardly predicted by the peripheral stress hormone assessments. ${ }^{50}$ Even in the absence of elevated HPA activity, however, it is noteworthy that CRH$\mathrm{COE}^{\text {hom }}$-Nes and -Cam mice display increased spontaneous REM sleep as most other animal models of depression do. ${ }^{51-55}$ It has been always difficult to dissociate the effects of each separate HPA hormone on sleep and to offer a mechanism how depression or stress promotes REM sleep. Exogenous administration of an unphysiologically high CRH dose triggers hyperarousal, leaving it unclear by which mechanism REM sleep is suppressed. ${ }^{43,56}$ So far, there are only few studies that have reported facets of CRH-mediating REM sleep promotion. ${ }^{20,57,58}$ However, certain stressors, such as immobilization, that is, an inescapable situation, are often reported to elicit REM sleep, ${ }^{5-61}$ which suggests an involvement of the CRH system in REM sleep regulation. ${ }^{23}$ These data yield a supposition that an acute HPA activation stimulates awakening, but its chronic activation or protracted recovery process from the acute hyperactivity produces a sleep phenotype resembling that seen in depressed patients. Our results suggest that a chronic site-specific overexpression of CRH induces REM sleep enhancement. This interpretation is not contradictory to that of Pawlyk et al. ${ }^{62}$ who microinjected CRH into the CeA of rats and observed a decrease in REM sleep. Notably not all the brain areas where our mouse mutants overexpress CRH are necessarily evoking the same effects on REM sleep. Also, CRH expression is differentially regulated in different regions of the limbic system. The herein demonstrated enhancement of REM sleep could be viewed as an endophenotype of elevated CRH in the forebrain, including limbic structures, which may correspond to REM sleep alteration in depressed patients ${ }^{63,64}$ or increased REM density as a clinical biomarker among individuals at high risk for affective disorders. ${ }^{65}$

This study is the first report showing that the brainderived CRH enhances REM sleep through the activation of CRHR1. This finding may indicate that CRHR1 antagonists are suited to restore impaired sleep and stress-related sleep disorders. Moreover, our site-specific CRH-COE mouse model suggests that $\mathrm{CRH}$ originating from the forebrain also contributes to REM sleep increase in patients with major depression. We emphasize that altered appearance of REM sleep is likely to be a premorbid sign of hypersecreted central CRH and may serve as biomarker predicting an upcoming clinical condition, which can be prevented by CRHR1 antagonists.

\section{Conflict of interest}

The authors declare no conflict of interest.

\section{Acknowledgments}

We thank M Dalal, T Fenzl, A Höhne, J Koepke, D Kohl, C Kühne, K Mayer, T Orschmann and C Romanowski for assisting with the study and A Steiger for helpful discussion. This work was supported by the Freedom to Discover Award, Bristol-Myers Squibb (FH), the Bundesministerium für Bildung und Forschung within the framework of the NGFN2 and NGFN-Plus (Förderkennzeichen 01GS0481 and 01GS08155; WW), the Fonds der Chemischen Industrie (JMD). We particularly acknowledge the donation of the CRHR1 antagonist (DMP696) by the late Jack Grebb from Bristol-Myers Squibb.

\section{References}

1 Vale W, Spiess J, Rivier C, Rivier J. Characterization of a 41-residue ovine hypothalamic peptide that stimulates secretion of corticotropin and $\beta$-endorphin. Science 1981; 213: 1394-1397.

2 Dunn AJ, Berridge CW. Physiological and behavioral responses to corticotropin-releasing factor administration: is CRF a mediator of anxiety or stress responses? Brain Res Rev 1990; 15: 71-100.

3 Habib KE, Gold PW, Chrousos GP. Neuroendocrinology of stress. Endocrinol Metab Clin North Am 2001; 30: 695-728.

4 Friess E, Wiedemann K, Steiger A, Holsboer F. The hypothalamicpituitary-adrenocortical system and sleep in man. Adv Neuroimmunol 1995; 5: 111-125.

5 Buckley TM, Schatzberg AF. On the interactions of the hypothalamic-pituitary-adrenal (HPA) axis and sleep: normal HPA axis activity and circadian rhythm, exemplary sleep disorders. J Clin Endocrinol Metab 2005; 90: 3106-3114.

6 Steiger A. Neurochemical regulation of sleep. J Psychiatr Res 2007; 41: 537-552.

7 Holsboer F, von Bardeleben U, Steiger A. Effects of intravenous corticotropin-releasing hormone upon sleep-related growth hormone surge and sleep EEG in man. Neurendocrinology 1988; 48: 32-38.

8 Born J, Spath-Schwalbe E, Schwakenhofer H, Kern W, Fehm HL. Influences of corticotropin-releasing hormone, adrenocorticotropin, and cortisol on sleep in normal man. J Clin Endocrinol Metab 1989; 68: 904-911.

9 Ehlers CL, Reed TK, Henriksen SJ. Effects of corticotropinreleasing factor and growth hormone-releasing factor on sleep and activity in rats. Neuroendocrinology 1986; 42: 467-474.

10 Chang FC, Opp MR. Corticotropin-releasing hormone (CRH) as a regulator of waking. Neurosci Biobehav Rev 2001; 25: 445-453.

11 Chastrette N, Clement HW, Prevautel H, Cespuglio R. Proopiomelanocortin components: differential sleep-waking regulation? In: Inoué S, Schneider-Helmert D (eds). Sleep Peptides: Basic and Clinical Approaches. Springer-Verlag: Tokyo/Berlin, 1988, pp 27-52. 
12 Bradbury MJ, Dement WC, Edgar DM. Effects of adrenalectomy and subsequent corticosterone replacement on rat sleep state and EEG power spectra. Am J Physiol 1998; 275: R555-R565.

$13 \mathrm{Lu}$ A, Steiner MA, Whittle N, Vogl AM, Walser SM, Ableitner M et al. Conditional mouse mutants highlight mechanisms of corticotropin-releasing hormone effects on stress coping behavior. Mol Psychiatry 2008; 13: 1028-1042.

14 Tronche F, Kellendonk C, Kretz O, Gass P, Anlag K, Orban PC et al. Disruption of the glucocorticoid receptor gene in the nervous system results in reduced anxiety. Nat Genet 1999; 23: 99-103.

15 Minichiello L, Korte M, Wolfer D, Kuhn R, Unsicker K, Cestari V et al. Essential role for TrkB receptors in hippocampus-mediated learning. Neuron 1999; 24: 401-414.

16 Louis RP, Lee J, Stephenson R. Design and validation of a computer-based sleep-scoring algorithm. J Neurosci Meth 2004; 133: $71-80$.

17 Maciag CM, Dent G, Gilligan P, He L, Dowling K, Ko T et al. Effects of a non-peptide CRF antagonist (DMP696) on the behavioral and endocrine sequelae of maternal separation. Neuropsychopharmacology 2002; 26: 574-582.

18 Borbely AA. A two process model of sleep regulation. Hum Neurobiol 1982; 1: 195-206.

19 Franken P, Chollet D, Tafti M. The homeostatic regulation of sleep need is under genetic control. J Neurosci 2001; 21: 2610-2621.

20 Marrosu F, Gessa GL, Giagheddu M, Fratta W. Corticotropinreleasing factor (CRF) increases paradoxical sleep (PS) rebound in PS-deprived rats. Brain Res 1990; 515: 315-318.

21 Groenink L, Dirks A, Verdouw PM, Schipholt M, Veening JG, van der Gugten J et al. HPA axis dysregulation in mice overexpressing corticotropin releasing hormone. Biol Psychiatry 2002; 51: 875-881.

22 Stenzel-Poore MP, Cameron VA, Vaughan J, Sawchenko PE, Vale W. Development of Cushing's Syndrome in corticotropinreleasing factor transgenic mice. Endocrinology 1992; 130: 3378-3386.

23 Gonzalez MM, Valatx JL. Effect of intracerebroventricular administration of alpha-helical CRH (9-41) on the sleep/waking cycle in rats under normal conditions or after subjection to an acute stressful stimulus. J Sleep Res 1997; 6: 164-170.

24 Chang FC, Opp MR. Role of corticotropin-releasing hormone in stressor-induced alterations of sleep in rat. Am J Physiol 2002; 283: R400-R407.

25 Held K, Antonijevic I, Murck H, Künzel H, Steiger A. Alphahelical CRH exerts CRH agonistic effects on sleep-endocrine activity in humans. Neuropsychobiology 2005; 52: 62-67.

26 De Kloet ER, Joëls M, Holsboer F. Stress and the brain: from adaptation to disease. Nat Rev Neurosci 2005; 6: 463-475.

27 Arborelius L, Owens MJ, Plotsky PM, Nemeroff CB. The role of corticotropin-releasing factor in depression and anxiety disorders. J Endocrinol 1999; 160: 1-12.

28 Holsboer F. The rationale for corticotropin-releasing hormone receptor (CRH-R) antagonists to treat depression and anxiety. J Psychiatr Res 1999; 33: 181-214.

29 Benca RM, Obermeyer WH, Thisted RA, Gillin JC. Sleep and psychiatric disorders. A meta-analysis. Arch Gen Psychiatry 1992; 49: $651-668$.

30 Thase ME, Kupfer DJ, Fasiczka AJ, Buysse DJ, Simons AD, Frank E. Identifying an abnormal electroencephalographic sleep profile to characterize major depressive disorder. Biol Psychiatry 1997; 41: 964-973.

31 Gray TS, Bingaman EW. The amygdala: corticotropin-releasing factor, steroids, and stress. Crit Rev Neurobiol 1996; 10: 155-168.

32 Amaral DG, Price JL, Pitkänen A, Carmichael ST. Anatomical organization of the primate amygdaloid complex. In: Aggleton JP (ed) The Amygdala: Neurobiological Aspects of Emotion, Memory, and Mental Dysfunction. Wiley-Liss: New York, 1992; pp: 1-66.

33 Valentino RJ, Page ME, Luppi PH, Zhu Y, Van Bockstaele E, AstonJones G. Evidence for widespread afferents to Barrington's nucleus, a brainstem region rich in corticotropin-releasing hormone neurons. Neuroscience 1994; 62: 125-143.

34 Quattrochi J, Datta S, Hobson JA. Cholinergic and non-cholinergic afferents of the caudolateral parabrachial nucleus: a role in the long-term enhancement of rapid eye movement sleep. Neuroscience 1998; 83: 1123-1136.
35 Lai YY, Siegel JM. Corticotropin-releasing factor mediated muscle atonia in pons and medulla. Brain Res 1992; 575: 63-68.

36 Smith CT, Miskiman DE. Increases in paradoxical sleep as a result of amygdaloid stimulation. Physiol Behav 1975; 15: 17-19.

37 Calvo JM, Simón-Arceo K, Fernández-Mas R. Prolonged enhancement of REM sleep produced by carbachol microinjection into the amygdala. Neuroreport 1996; 7: 577-580.

38 Wiersma A, Konsman JP, Knollema S, Bohus B, Koolhaas JM. Differential effects of CRH infusion into the central nucleus of the amygdala in the Roman high-avoidance and low-avoidance rats. Psychoneuroendocrinology 1998; 23: 261-274.

39 Benca RM, Obermeyer WH, Shelton SE, Droster J, Kalin NH. Effects of amygdala lesions on sleep in rhesus monkeys. Brain Res 2000; 879: 130-138.

40 Maquet P, Peters J, Aerts J, Delfiore G, Degueldre C, Luxen A et al. Functional neuroanatomy of human rapid-eye-movement sleep and dreaming. Nature 1996; 383: 163-166.

41 Nofzinger E, Mintun M, Wiseman M, Kupfer D, Moore R. Forebrain activation in REM sleep: an FDG PET study. Brain Res 1997; 770: 192-201.

42 Moga MM, Gray T. Evidence for corticotropin-releasing factor, neurotensin, and somatostatin in the neural pathway from the central nucleus of the amygdala to the parabrachial nucleus. J Comp Neurol 1985; 241: 275-284.

43 Romanowski C, Fenzl T, Flachskamm C, Deussing JM, Kimura M. CRH-R1 is involved in effects of CRH on NREM, but not REM, sleep suppression. Sleep Biol Rhythms 2007; 5(suppl 1): A53.

44 Grammatopoulos DK, Crousos GP. Functional characteristics of $\mathrm{CRH}$ receptors and potential clinical applications of CRH-receptor antagonists. Trends Endocrinol Metab 2002; 13: 436-444.

45 Marinesco S, Bonnet S, Cespuglio R. Influence of stress duration on the sleep rebound induced by immoblization in the rat: a possible role for corticosterone. Neuroscience 1999; 92: 921-933.

46 Nemeroff CB, Widerlov E, Bissette G, Walleus H, Karlsson I, Eklund $\mathrm{K}$ et al. Elevated concentrations of CSF corticotropinreleasing factor-like immunoreactivity in depressed patients. Science 1984; 226: 1342-1344.

47 Raadsheer FC, van Heerikhuize JJ, Lucassen PJ, Hoogendijk WJ, Tilders FJ, Swaab DF. Corticotropin-releasing hormone mRNA levels in the paraventricular nucleus of patients with Alzheimer's disease and depression. Am J Psychiatry 1995; 152: 1372-1376.

48 Wong ML, Kling MA, Munson PJ, Listwak S, Licinio J, Prolo P et al. Pronounced and sustained central hyperadrenergic function in major depression with melancholic features: relation to hypercortisolism and corticotropin-releasing hormone. Proc Natl Acad Sci USA 2000; 97: 325-330.

49 Henn FA, Vollmayr B. Stress models of depression: forming genetically vulnerable strains. Neurosci Biobehav Rev 2005; 29: 799-804.

50 Zobel AW, Nickel T, Künzel HE, Ackl N, Sonntag A, Ising M et al. Effects of the high-affinity corticotropin-releasing hormone receptor 1 antagonist R121919 in major depression: the first 20 patients treated. J Psychiatr Res 2000; 34: 171-181.

51 Dugovic C, Maccari S, Weibel L, Turek FW, Van Reeth O. High corticosterone levels in prenatally stressed rats predict persistent paradoxical sleep alterations. J Neurosci 1999; 19: 8656-8664.

52 Dugovic C, Solberg LC, Redei E, Van Reeth O, Turek FW. Sleep in the Wister-Kyoto rat, a putative genetic animal model for depression. Neuroreport 2000; 11: 627-631.

53 El Yacoubi M, Bouali S, Popa D, Naudon L, Leroux-Nicollet I, Hamon $\mathrm{M}$ et al. Behavioral, neurochemical, and electrophysiological characterization of a genetic mouse model of depression. Proc Natl Acad Sci USA 2003; 100: 6227-6232.

54 Overstreet DH, Friedman E, Mathé AA, Yadid G. The Flinders Sensitive Line rat: a selectively bred putative animal model of depression. Neurosci Biobehav Rev 2005; 29: 739-759.

55 Touma C, Fenzl T, Ruschel J, Palme R, Holsboer F, Kimura M et al. Rhythmicity in mice selected for extremes in stress reactivity: behavioural, endocrine and sleep changes resembling endophenotypes of major depression. PLOS ONE 4: e4325.

56 Sanford LD, Yang L, Wellman LL, Dong E, Tang X. Mouse strain differences in the effects of corticotropin-releasing hormone (CRH) on sleep and wakefulness. Brain Res 2008; 1190: 94-104. 
57 Gonzalez MM, Valatx JL. Involvement of stress in the sleep rebound mechanism induced by sleep deprivation in the rat: use of alpha-helical CRH (9-41). Behav Pharmacol 1998; 9: 655-662.

58 Feng P, Liu X, Vurbic D, Fan H, Wang S. Neonatal REM sleep is regulated by corticotropin-releasing factor. Behav Brain Res 2007; 182: 95-102.

59 Rampin C, Cespuglio R, Chastrette N, Jouvet M. Immobilisation stress induces a paradoxical sleep rebound in rat. Neurosci Lett 1991; 126: 113-118.

60 Bouyer JJ, Vallée M, Deminière JM, Le Moal M, Mayo W. Reaction of sleep-wakefulness cycle to stress is related to differences in hypothalamo-pituitary-adrenal axis reactivity in rat. Brain Res 1998; 804: 114-124

61 Koehl M, Bouyer JJ, Darnaudéry M, Le Moal M, Mayo W. The effect of restraint stress on paradoxical sleep is influenced by the circadian time. Brain Res 2002; 937: 45-50.

62 Pawlyk AC, Sanford LD, Brennan FX, Morrison AR, Ross RJ. Corticotropin-releasing factor microinjection into the central nucleus of the amygdala alters REM sleep. Pharmacol Rep 2006; 58: 125-130.
63 McCarley RW. REM sleep and depression: common neurobiological control mechanisms. Am J Psychiatry 1982; 139: 565-570.

64 Gottesmann C, Gottesman I. The neurobiological characteristics of rapid eye movement (REM) sleep are candidate endophenotypes of depression, schizophrenia, mental retardation and dementia. Prog Neurobiol 2007; 81: 237-250.

65 Modell S, Ising M, Holsboer F, Lauer CJ. The Munich vulnerability study on affective disorders: premorbid polysomnographic profile of affected high-risk probands. Biol Psychiatry 2005; 58: 694-699.

This work is licensed under the Creative
Commons Attribution-NonCommercial-
No Derivative Works 3.0 License. To view a copy
of this license, visit http://creativecommons.org/
licenses/by-nc-nd/3.0/

Supplementary Information accompanies the paper on the Molecular Psychiatry website (http://www.nature.com/mp) 